Check for updates

Cite this: RSC Adv., 2017, 7, 36000

\title{
Fabrication of $\mathrm{AgBr} /$ boron-doped reduced graphene oxide aerogels for photocatalytic removal of $\mathrm{Cr}(\mathrm{vI})$ in water $\dagger$
}

\author{
Yiqiao Huang, ${ }^{\text {a }}$ Chengling Zhu, ${ }^{a}$ Hui Pan, ${ }^{a}$ Da Xu, ${ }^{a}$ Tao Lu, ${ }^{a}$ Lin Mao, ${ }^{b}$ Xin Meng, ${ }^{a}$ \\ Zhixin Chen, ${ }^{c}$ Di Zhang ${ }^{a}$ and Shenmin Zhu (D) *ad
}

\begin{abstract}
$\mathrm{AgBr}$ nanoparticles on boron-doped reduced graphene oxide aerogels ( $\mathrm{AgBr} / \mathrm{B}-\mathrm{RGO}$ ) are synthesized by a facile hydrothermal method, which shows a superior performance in the photoreduction of toxic hexavalent chromium $\left(\mathrm{Cr}^{\mathrm{V}}\right)$ in aqueous media under visible light irradiation. The composition and structure of the samples have been characterized by using XPS, Raman, XRD, TEM and SEM measurements. As compared with that of $\mathrm{AgBr}$ on none-doped reduced graphene oxide aerogels ( $\mathrm{AgBr} /$ $\mathrm{RGO}$ ), the improved photocatalytic properties, can be attributed to the introduction of boron atoms in reduced graphene oxide (RGO), bringing in the improvement of electron transfer efficiency, and the depression of the recombination of photo-excited electrons and holes. Further tests in the photoreduction of $\mathrm{Cr}^{\mathrm{Vl}}$ reveal that the obtained $\mathrm{AgBr} / \mathrm{B}-\mathrm{RGO}$ presents excellent cycling performance with an interesting increase in the photocatalytic efficiency upon cycling number. This observation can be explained by the fact that the gradual emergence of $\mathrm{Ag}^{\mathrm{O}}$ formed from the photo-induced decomposition of $\mathrm{AgBr}$, introduces a Surface Plasmon Resonance (SPR) effect to the system. The approach herein reported could be extended to the design and fabrication of other photocatalysts with high performance that combine the boron-doped graphene and SPR effect.
\end{abstract}

Received 23rd May 2017

Accepted 12th July 2017

DOI: 10.1039/c7ra05770a

rsc.li/rsc-advances

\section{Introduction}

Graphene, a two dimensional honey-comb structure crystal, has been extensively applied with semiconductors and noble metal nanoparticles as nanocomposites for photocatalysis due to its excellent performance in transferring electrons. ${ }^{1-6}$ The graphene-based composites can be applied in various fields, like batteries, ${ }^{7}$ general organic and hybrid photovoltaics, ${ }^{8-11}$ transistors, ${ }^{12}$ biology ${ }_{13}$ hydrogen storage,${ }^{14}$ and field-emission cathodes..$^{15} \mathrm{~A}$ great number of researchers have used graphene as the matrix to load nanoparticles where graphene can play a critical role in restraining the recombination of photo-excited electrons and photo-excited holes, and prevent the process of aggregation of the nanoparticles. ${ }^{3,16-20}$ Generally, the common semiconductors selected for attaching to graphene are metal oxides and sulfides, such as $\mathrm{TiO}_{2},{ }^{17,21-24} \mathrm{ZnO},{ }^{25-27} \mathrm{WO}_{3}$

${ }^{a}$ State Key Laboratory of Metal Matrix Composites, Shanghai Jiao Tong University, Shanghai 200240, China. E-mail: smzhu@sjtu.edu.cn; Fax: +86 213420 2749; Tel: +862134202584

${ }^{b}$ Shanghai Hiwave Composite Materials Co., Ltd, China

${ }^{c}$ Engineering Materials Institute, School of Mechanical, Materials \& Mechatronics Engineering, University of Wollongong, NSW 2500, Australia

${ }^{d}$ National Engineering Research Center for Nanotechnology, China

$\dagger$ Electronic supplementary information (ESI) available. See DOI: 10.1039/c7ra05770a (ref. 28-30) and CdS. ${ }^{31-33}$ Recently, silver halides have become a promising n-type semiconductor as the key role in the photocatalysis nanocomposites with graphene due to their extraordinary sensitivity to visible light and outstanding photocatalytic performance. ${ }^{34,35}$

Commonly, the graphene used in such research is produced through the reduction of graphene oxide (GO), which would introduce defections such as hydroxyl and carboxyl group into the structure of graphene, depressing the electrons transferring property and increasing the defects of graphene, leading to the decrease of photocatalytic efficiency of the photocatalysis. ${ }^{36-38}$ To solve this problem, two common methods are utilized: one is to construct graphene to a 3D structure aerogel ${ }^{39}$ due to improved electron transport properties. And the other is to dope graphene with heteroatoms (e.g., B, N, P and S), ${ }^{40-48}$ attributing to the enhancement of electron transport property and conductivity. Among these heteroatoms, nitrogen atom has been applied widely in the field of photocatalysis. Nitrogen atom can provide extra pelectrons to the $\pi$-bonding system, giving rise to the increase of carrier's density and then enhance the electron transportation speed in graphene. ${ }^{38}$ Thus, the recombination between the photo-excited electrons and holes would be reduced, and the photocatalytic performance is enhanced..$^{38}$ What's more, as the neighbor element of carbon, nitrogen substitutional doping in graphene lattice can conserve $\mathrm{sp}^{2}$ 
bonding structure, leading to the decrease of defection caused by $\mathrm{sp}^{3}$ bonding. ${ }^{38}$ Like nitrogen, boron is also a neighbor element of carbon..$^{45}$ That is the reason of why the researches on boron-doped reduced graphene oxide (B-RGO) is of great interest, recently. ${ }^{45-47,49}$ Different from nitrogen, the introduction of boron atom will provide extra p-orbit to the $\pi$-bonding system, serving as powerful charge accepting center to promote the charge transfer, which is beneficial to photocatalyst. $^{38}$ Tang et al. reported that boron-doped graphene presented over 5 times higher photocatalytic efficiency in decomposing of Rhodamine $\mathrm{B}(\mathrm{RhB})$ than that of nonedoped graphene. ${ }^{45}$ The superior photocatalytic activity is attributed to the higher efficiency of electron transferring from the excited state of RhB to B-RGO. ${ }^{45}$ Moreover, as compared with none-doped graphene, B-RGO is more suitable for composite system. ${ }^{47,50}$ B-RGO owns property of p-type semiconductor. ${ }^{47,51}$ When combined with n-type semiconductor such as $\mathrm{TiO}_{2}{ }^{47}$ the $\mathrm{p}-\mathrm{n}$ junction will emerge, which can restrict the recombination of photo-excited electrons and holes, thus improves the photocatalytic efficiency.

To the best of our knowledge, researches on the photocatalytic activity of B-RGO mainly focus on the oxidation of organic photosensitive dyes such as $\mathrm{RhB}^{45}$ and methylene blue. ${ }^{52}$ Little attention has been paid to the application of B-RGO in dealing with removal of heavy metal ions through photocatalysis in polluted water, such as hexavalent chromium $\left(\mathrm{Cr}^{\mathrm{VI}}\right) . \mathrm{Cr}^{\mathrm{VI}}$, a carcinogenic and high toxic heavy metal pollutant, widely exists in the waste water originated from electroplating industry, leather industry and pigment manufacture..$^{53-55}$ It has been reported that $\mathrm{Cr}^{\mathrm{VI}}$ can be directly reduced to non-toxic trivalent chromium by photo-excited electron during photocatalysis reaction. ${ }^{56}$ This means the increase of the density of photo-excited electrons and the decrease of the recombination of photo-excited electronsholes pairs will effectively improve the photoreduction efficiency. In other words, choosing a proper semiconductor will benefit the photoreduction reaction. Silver bromide (AgBr), a n-type semiconductor with excellent sensitivity to visible light, ${ }^{57,58}$ can produce photo-excited electrons under light irradiation. Furthermore, it has been reported that part of $\mathrm{AgBr}$ nanoparticles will break into silver nanoparticles $\left(\mathrm{Ag}^{0}\right)$, whose Surface Plasmon Resonance (SPR) under light illumination is expected to generate extra electrons to promote the photoreduction process. ${ }^{56,58}$

In this work, we design the preparation of $\mathrm{AgBr} /$ boron-doped reduced graphene oxide aerogels ( $\mathrm{Ag} \mathrm{Br} / \mathrm{B}-\mathrm{RGO})$ and investigate the photoreduction efficiency of removing hexavalent chromium in water. Particularly, the resultant $\mathrm{AgBr} / \mathrm{B}-\mathrm{RGO}$ was constructed into aerogel, which is beneficial to the recycle test and practical application. As compared with the sample of $\mathrm{AgBr}$ nanoparticles on none-doped reduced graphene oxide aerogels (AgBr/RGO), AgBr/B-RGO shows an improved photocatalytic property on the photoreduction of hexavalent chromium. More interesting is, $\mathrm{AgBr} / \mathrm{B}-\mathrm{RGO}$ performs well in the cycling photocatalysis tests. The mechanism has been proposed and discussed based on the results.

\section{Experimental}

Graphene oxide (GO) is prepared by using a modified Hummers' method. The detailed description is displayed in (ESI $\dagger$ ). Here, the synthesis of $\mathrm{AgBr} / \mathrm{B}-\mathrm{RGO}$ is described in Fig. 1. At first, $3 \mathrm{~mL}$ of $\mathrm{H}_{3} \mathrm{BO}_{3}$ solutions $\left(50.2 \mathrm{~g} \mathrm{~L}^{-1}\right)$ was added into 4 $\mathrm{mL}$ of $\mathrm{GO}$ solution $\left(7.5 \mathrm{~g} \mathrm{~L}^{-1}\right)$, and then, $8 \mathrm{~mL}$ of deionized water was added into the mixture under vigorous stirring for 30 minutes. Then, the mixture was undergoing ultrasonic process for 15 minutes, accompanied by ice bath to prevent the temperature going up too high. Subsequently, the mixture was transferred into a Teflon-scaled autoclave and kept at $180{ }^{\circ} \mathrm{C}$ for $12 \mathrm{~h}$ to generate reduced graphene oxide aerogels. The obtained reduce graphene oxide aerogels were immersed into $14 \mathrm{~mL}$ solution of CTAB ( $8.5 \mathrm{~g}$ CTAB dissolved in the mixture of $250 \mathrm{~mL}$ ethanol and $750 \mathrm{~mL}$ deionized water) at $80{ }^{\circ} \mathrm{C}$ for $7 \mathrm{~h}$. Then, immersed into $14 \mathrm{~mL}$ solution of $\mathrm{AgNO}_{3}\left(2.6112 \mathrm{~g} \mathrm{~L}^{-1}\right)$ for $30 \mathrm{~min}$. Finally, the synthesized aerogels were washed by deionized water for several times and processed by freezedrying to get AgBr/B-RGO.

\section{Results and discussion}

Firstly, the morphology of the obtained AgBr/B-RGO is investigated by scanning electron microscope (SEM) and transmission electron microscope (TEM) as presented in Fig. 2. Obviously, $\mathrm{AgBr} / \mathrm{B}-\mathrm{RGO}$ possess a 3-dimensional structure (Fig. 2(a)) with $\mathrm{AgBr}$ nanoparticles uniformly distributing on the surface of BRGO without obvious aggregation (Fig. 2(b)). The size of the $\mathrm{AgBr}$ nanoparticles is determined around the range of 100 to $150 \mathrm{~nm}$ through the high magnification SEM image in Fig. 2(c) and TEM image in Fig. 2(d). In contrast, pure AgBr nanoparticles synthesized under the same condition without the matrix B-RGO, have a large particle size of more than $1500 \mathrm{~nm}$ and aggregation occurred among the particles (Fig. S1 in ESI†). Further comparison of the sample prepared from $\mathrm{AgBr}$ growing on reduced graphene oxide without B-doping ( $\mathrm{AgBr} / \mathrm{RGO}$ ) (Fig. S2 $\dagger$ ), the particle size of $\mathrm{AgBr}$ is detected to be similar as that of $\mathrm{AgBr}$ in $\mathrm{AgBr} / \mathrm{B}-\mathrm{RGO}$. That means, the introduction of reduced graphene oxide (RGO) can effectively restrain the

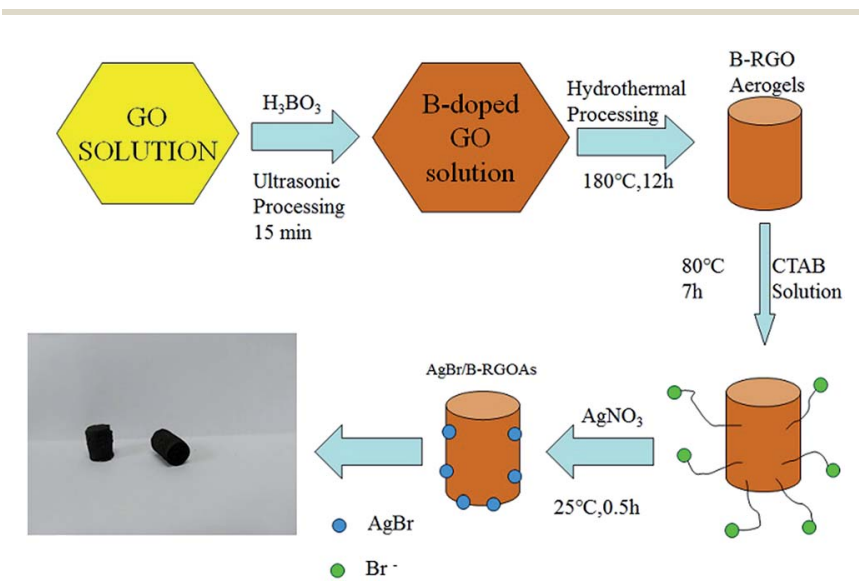

Fig. 1 Schematic description of the synthesis of $\mathrm{AgBr} / \mathrm{B}-\mathrm{RGO}$. 

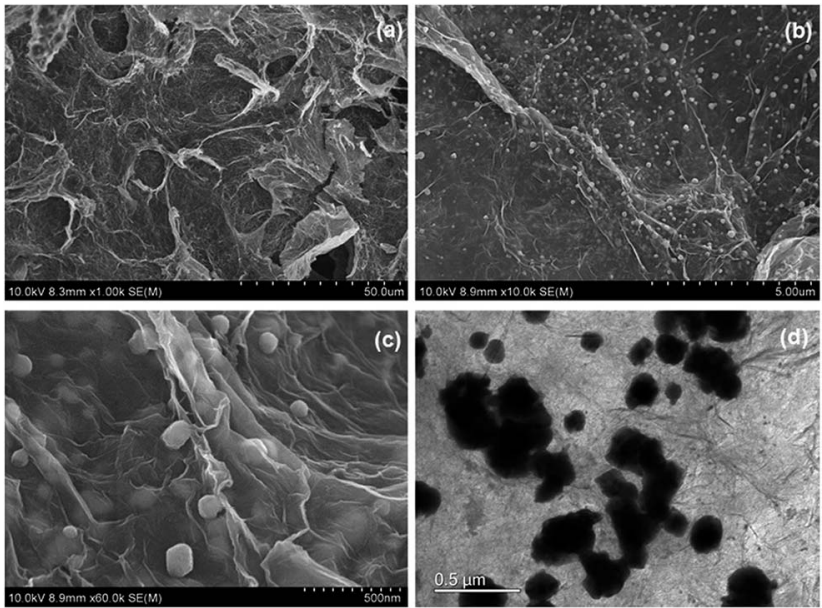

Fig. 2 (a), (b) and (c) SEM images of $\mathrm{AgBr} / \mathrm{B}-\mathrm{RGO}$ at different magnifications; (d) TEM image of $\mathrm{AgBr} / \mathrm{B}-\mathrm{RGO}$.

aggregation of $\mathrm{AgBr}$ nanoparticles during the fabrication process. Energy Dispersive X-ray (EDX) analysis spectra (Fig. 3(b)) and the related element mapping (Fig. 3(c)-(e)) are applied to verify the distribution of elements in AgBr/B-RGO. Four kinds of elements (C, O, $\mathrm{Ag}$ and $\mathrm{Br}$ ) are identified, as shown in Fig. 3(b) and the unmarked peaks belong to Pt. Obviously, C (Fig. 3(c)), Ag (Fig. 3(d)) and Br (Fig. 3(e)) are confirmed to disperse homogeneously in the selected area of $\mathrm{AgBr} / \mathrm{B}-\mathrm{RGO}$. Unfortunately, no boron can be detected, due to the small content in the composite. It should be mentioning that the existence of Pt is detected, originating from Pt coating process for SEM measurement.

The composition is further determined by using XPS characterization. Fig. 4(a) shows the C 1s XPS result of AgBr/B-RGO. The peak of $\mathrm{C}$ 1s can be deconvoluted into five peaks at 284.6, 285.3, 285.7, 286.8 and $288.4 \mathrm{eV}$, among which the peak at
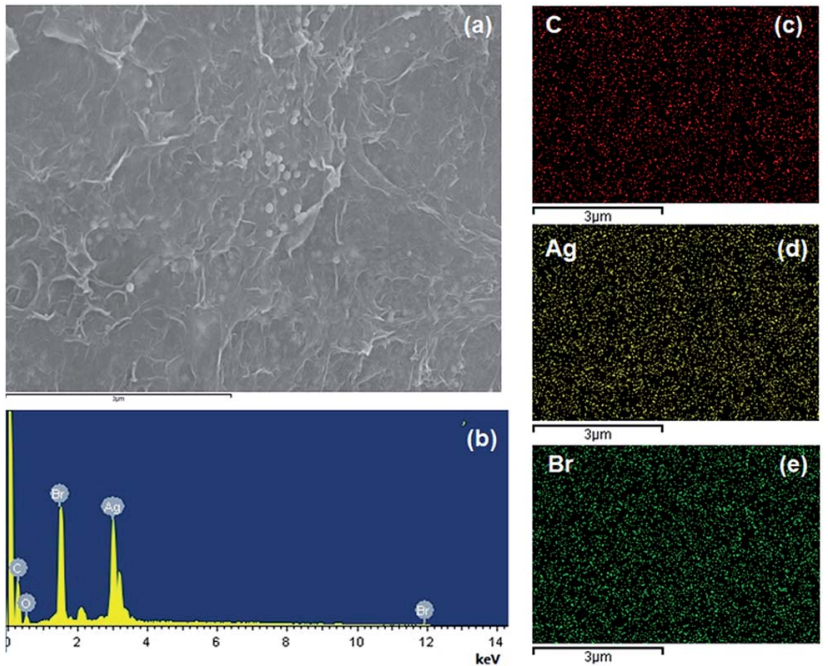

Fig. 3 (a) SEM image of the selected area to conduct EDX measurement; (b) the EDX result of $\mathrm{AgBr} / \mathrm{B}-\mathrm{RGO}$ and the element mapping images for $\mathrm{C}(\mathrm{c}), \mathrm{Ag}(\mathrm{d})$ and $\mathrm{Br}(\mathrm{e})$.
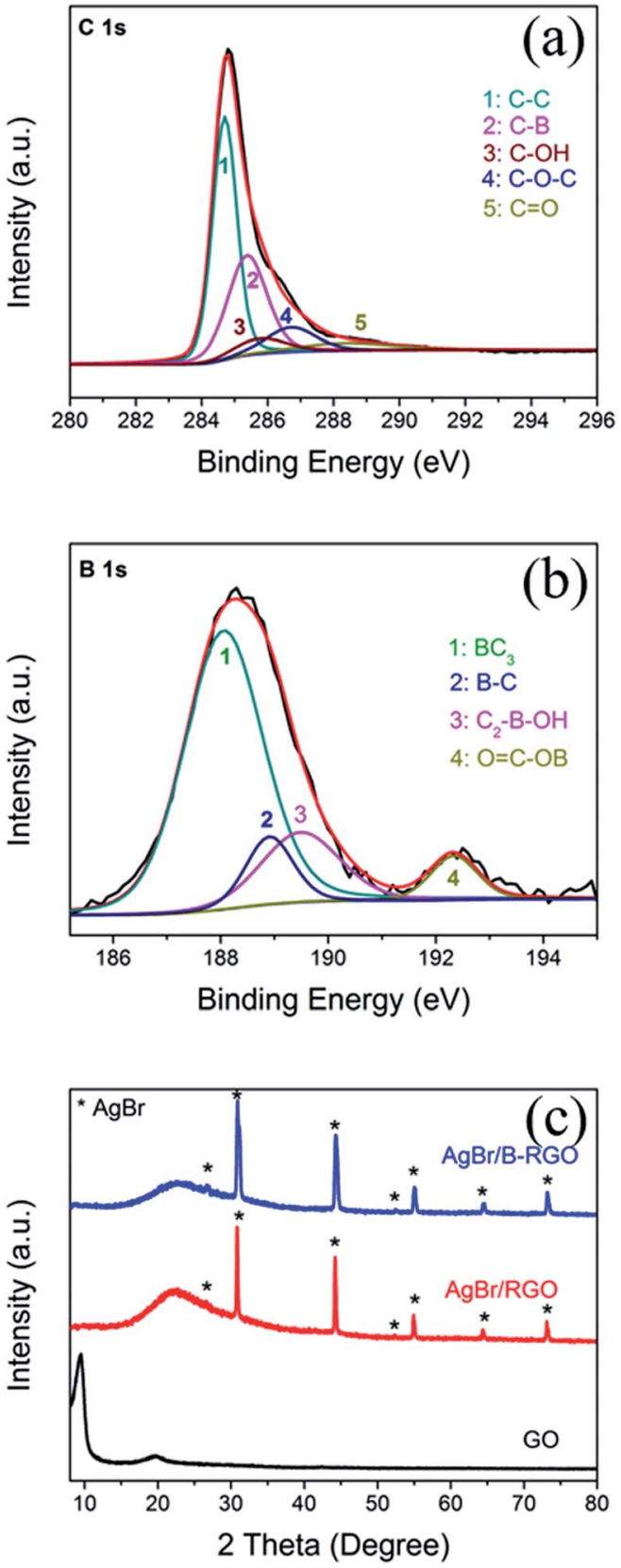

Fig. 4 (a) XPS spectrum of $C$ 1s of $A g B r / B-R G O$; (b) XPS spectrum of $B$ 1s of $\mathrm{AgBr} / \mathrm{B}-\mathrm{RGO}$; (c) XRD patterns of $\mathrm{GO}, \mathrm{AgBr} / \mathrm{RGO}$ and $\mathrm{AgBr} / \mathrm{B}-$ RGO.

285.3 eV gives the evidence of the $\mathrm{C}-\mathrm{B}$ bonding in $\mathrm{AgBr} / \mathrm{B}-\mathrm{RGO}$, while 284.6, 285.7, 286.8 and $288.4 \mathrm{eV}$ correspond to $\mathrm{C}-\mathrm{C}$ bonding, $\mathrm{C}-\mathrm{OH}$ bonding, $\mathrm{C}-\mathrm{O}-\mathrm{C}$ bonding and $\mathrm{C}=\mathrm{O}$ bonding. ${ }^{46}$ This result has proved the existence of boron atoms, and the boron atoms can interact with other atoms and form chemical bonding. Additionally, compared to XPS spectrum of $\mathrm{C}$ 1s of GO (Fig. S3 $†$ ), the distinct intensity decrease of $\mathrm{C}-\mathrm{OH}, \mathrm{C}-\mathrm{O}-\mathrm{C}$ and $\mathrm{C}=\mathrm{O}$ bonding indicates the reduction of $\mathrm{GO}$ since most of oxygen-containing groups are removed. Fig. 4(b) exhibits the B 1s peak. The boron species are $\mathrm{BC}_{3}(187.9 \mathrm{eV}), \mathrm{B}-\mathrm{C}(189 \mathrm{eV})$, $\mathrm{C}_{2}-\mathrm{B}-\mathrm{OH}(189.6 \mathrm{eV})$ and $\mathrm{O}=\mathrm{C}-\mathrm{OB}(192.2 \mathrm{eV}),{ }^{46,59}$ corresponding to peak 1, 2, 3 and 4, respectively. The XPS result indicates that 
the atomic concentration of boron atoms in $\mathrm{AgBr} / \mathrm{B}-\mathrm{RGO}$ is $0.35 \%$, and the molar ratio of $\mathrm{B} / \mathrm{C}$ atom is $1 / 248.7$. In comparison with that reported, our spectrum does not show the peak at $193.1 \mathrm{eV}$ in XPS spectrum of $\mathrm{B} 1 \mathrm{~s}$, corresponding to $\mathrm{B}_{2} \mathrm{O}_{3} \cdot{ }^{46}$ It is reasonable to conclude that the doped boron atoms are well doped into the structure of RGO, and form bonding with RGO.

The crystal structures of GO, AgBr/RGO and AgBr/B-RGO are revealed by X-ray diffraction (XRD) patterns (Fig. 4(c)). The distinct diffraction peaks $(2 \theta)$ at $26.7^{\circ}, 31.0^{\circ}, 44.4^{\circ}, 52.5^{\circ}, 55.1^{\circ}$, $64.5^{\circ}, 73.2^{\circ}$ belong to (111), (200), (220), (311), (222), (400) and (420) crystal planes of $\mathrm{AgBr}$, respectively (JCPDS file: 06-0438). In terms of $\mathrm{AgBr} / \mathrm{RGO}$ and $\mathrm{AgBr} / \mathrm{B}-\mathrm{RGO}$, the characteristic peak belonging to (002) phase of GO at $10.0^{\circ}$ in the XRD spectra shifts to higher angles after hydrothermal process due to the reduction of GO.

The properties of $\mathrm{AgBr} / \mathrm{B}-\mathrm{RGO}$ are investigated by photoreduction of $\mathrm{Cr}^{\mathrm{VI}}$ under visible light. The concentration of $\mathrm{Cr}^{\mathrm{VI}}$ can be well measured through recording the absorbance at $540 \mathrm{~nm}$ in the UV-vis spectra. As shown in the Fig. S4, $\dagger$ the intensity of absorbance of $\mathrm{Cr}^{\mathrm{VI}}$ significantly decreases as the reaction begins from 0 minutes, indicating the successful reduction of $\mathrm{Cr}^{\mathrm{VI}}$. The photocatalytic performance of $\mathrm{AgBr} / \mathrm{B}-$ RGO, $\mathrm{AgBr} / \mathrm{RGO}$, and pure $\mathrm{AgBr}$ are measured and compared in Fig. 5. Apparently, the introduction of RGO can enhance the photocatalytic efficiency of $\mathrm{AgBr}$, while the doped boron atoms in RGO structure can further strengthen the photocatalytic efficiency. In order to compare the decrease caused by photoreduction, $\ln \left(C_{0} / C\right)$ - time plot is displayed in Fig. 5(b). Initially, the difference between $\mathrm{AgBr} / \mathrm{B}-\mathrm{RGO}$ and $\mathrm{AgBr} / \mathrm{RGO}$ is not obvious until 30 minutes. The final photoreduction efficiency of $\mathrm{AgBr} / \mathrm{B}-\mathrm{RGO}$ reached a high value of $95.80 \%$. It should be mentioned that the dark absorptive curve of AgBr/B-RGO implies that the decrease of intensity of $\mathrm{Cr}^{\mathrm{VI}}$ is attributed to the photoreduction process to a great extent, rather than absorption.

Cycling tests of photoreduction of $\mathrm{Cr}^{\mathrm{VI}}$ on $\mathrm{AgBr} / \mathrm{B}-\mathrm{RGO}$ are carried out as shown in Fig. 6. To approximately evaluate the change of reaction rate, linear fitting is applied to get the slope $k_{\mathrm{a}}$, of $C / C_{0}$ - time plots, which has positive relationship with reaction rate. Table 1 summarized the $k_{\mathrm{a}}$ and the final $C / C_{0}$ of the six times cycling test. Interestingly, the final $C / C_{0}$ value of the photoreduction gradually decreases as the reaction cycling number goes up, indicating that the reduction rate increases
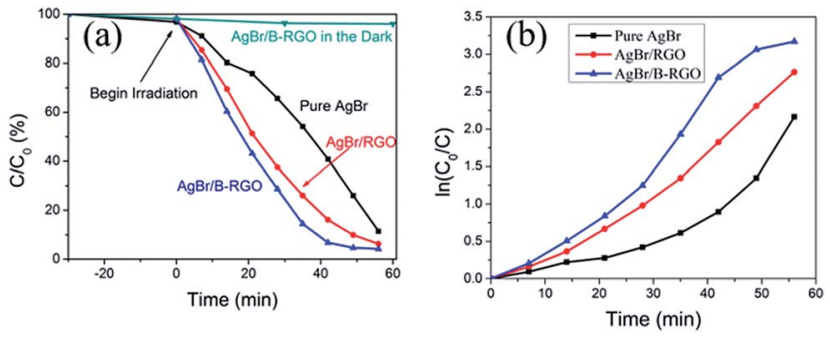

Fig. 5 (a) Photoreduction of $\mathrm{Cr}^{\mathrm{Vl}}$ by $\mathrm{AgBr} / \mathrm{B}-\mathrm{RGO}, \mathrm{AgBr} / \mathrm{RGO}$ and pure $\mathrm{AgBr}$ under light irradiation and the absorptive curve of $\mathrm{AgBr} / \mathrm{B}-\mathrm{RGO}$ in darkness; (b) $\ln \left(C_{0} / C\right)$ - time plot.

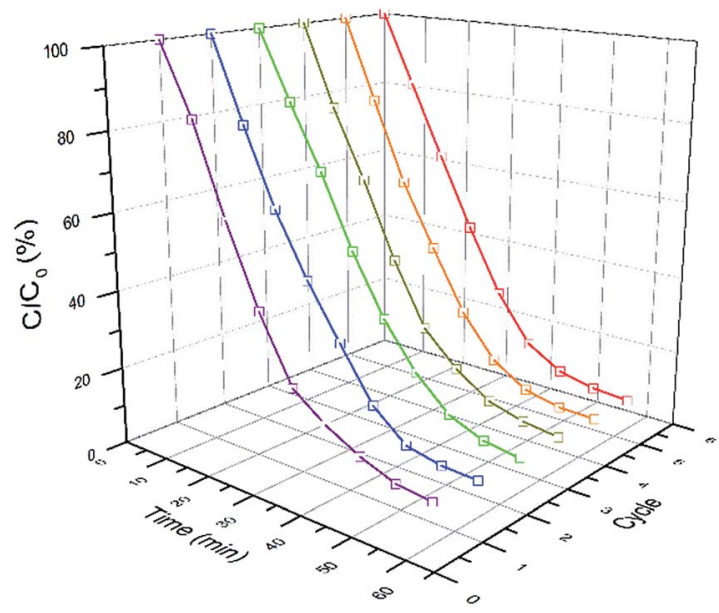

Fig. 6 Six successive photoreduction of $\mathrm{Cr}^{\mathrm{VI}}$ over $\mathrm{AgBr} / \mathrm{B}-\mathrm{RGO}$.

Table 1 The $k_{\mathrm{a}}$ and the final $\mathrm{C} / \mathrm{C}_{0}$ of the photoreduction of the six times cycling tests over AgBr/B-RGO

\begin{tabular}{lllllll}
\hline Cycling times & 1 & 2 & 3 & 4 & 5 & 6 \\
\hline$k_{\mathrm{a}}$ & 0.058 & 0.064 & 0.063 & 0.064 & 0.070 & 0.070 \\
$C / C_{0}{ }^{a}$ & $5.01 \%$ & $4.02 \%$ & $3.78 \%$ & $3.61 \%$ & $3.08 \%$ & $2.97 \%$
\end{tabular}

${ }^{a}$ Final $C / C_{0}$ after reaction of 56 minutes.

during circulation tests. In other word, the photocatalytic efficiency of AgBr/B-RGO increases along with the cycling number.

In order to find the reason, the phase structure of $\mathrm{AgBr} / \mathrm{B}-$ RGO after photocatalysis reaction was determined by using XRD. Shown in Fig. $7(\mathrm{a})$, the peaks at $38.1^{\circ}, 44.3^{\circ}$ and $64.4^{\circ}$ can be attributed to the (111), (200), (220) crystal planes of elemental silver ( $\mathrm{Ag}^{0}$, JCPDS file: 04-0783). Moreover, high resolution TEM image displayed in Fig. 7(b) indicates the lattice spacing of $0.236 \mathrm{~nm}$, corresponding to the (111) plane of silver crystal and the lattice spacing of $0.174 \mathrm{~nm}$, corresponding to the (311) plane of $\mathrm{AgBr}$ crystal (JCPDS file: 06-0438). That means $\mathrm{Ag}^{\mathrm{O}}$ generated from $\mathrm{AgBr}$ during the photocatalytic tests, as reported by others. ${ }^{56}$

To clarify the mechanism of the improved photocatalytic ability of $\mathrm{AgBr} / \mathrm{B}-\mathrm{RGO}$ in comparison with $\mathrm{AgBr} / \mathrm{RGO}$, Raman spectroscopy has been performed shown in Fig. 8(a). The average $I_{\mathrm{D}} / I_{\mathrm{G}}$ value of $\mathrm{AgBr} / \mathrm{B}-\mathrm{RGO}$ is 0.72 , lower than that of $\mathrm{AgBr} / \mathrm{RGO}(0.79)$ and GO (0.89) (the error bars are presented in Fig. S5 $\dagger$ ). This suggests the less density of defect in AgBr/B-RGO, compared to AgBr/RGO. Additionally, the electrochemical impedance spectroscopy (EIS) analysis has been conducted to characterize the charge carrier migration property of materials serving as electrodes. ${ }^{29,37}$ The EIS plot of AgBr/B-RGO presents a depressed arc compared to that of AgBr/RGO (Fig. 8(b)), indicating less resistance of charge carriers in AgBr/B-RGO. This is caused by the enlarged density of states (DOS) value near the Fermi level, ${ }^{45}$ which will benefit the electronic conductivity in the samples. Therefore, the introduction of boron atoms to the structure of RGO can improve the efficiency of electron transfer 

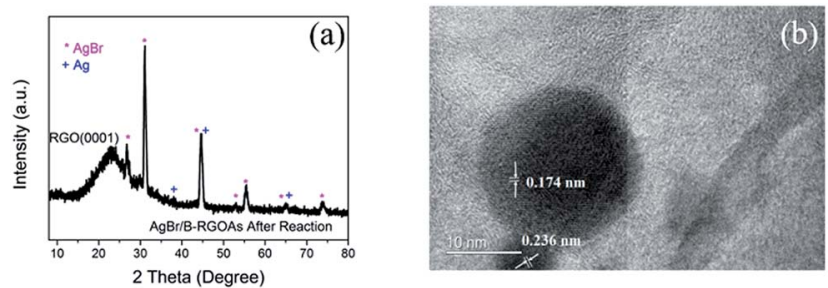

Fig. 7 (a) XRD pattern of AgBr/B-RGO after reaction; (b) HRTEM image of $\mathrm{AgBr}$ and $\mathrm{Ag}^{\mathrm{O}}$
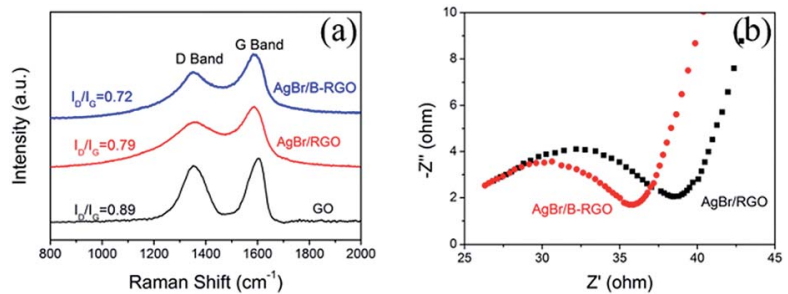

Fig. 8 (a) Raman spectra of AgBr/B-RGO, AgBr/RGO and GO; (b) EIS Nyquist plots of $\mathrm{AgBr} / \mathrm{B}-\mathrm{RGO}$ and $\mathrm{AgBr} / \mathrm{RGO}$.

and promote electronic conductivity by decreasing defect density in $\mathrm{AgBr} / \mathrm{B}-\mathrm{RGO}$. This results the inhibition of the recombination of photo-excited electrons and holes, contributing to the high photocatalytic activity for the reduction $\mathrm{of} \mathrm{Cr}^{\mathrm{VI}}$ in water.

The mechanism of $\mathrm{Cr}^{\mathrm{VI}}$ photo-reduction over $\mathrm{AgBr} / \mathrm{B}-\mathrm{RGO}$ is explained in Fig. 9. Initially, there exists no $\mathrm{Ag}^{0}$, when light irradiation starts, photons hits the $\mathrm{AgBr}$ nanoparticles, and photo-excited electrons will transfer to the conduct band (CB) of $\mathrm{AgBr}$ and leaves photo-excited holes in the valence band (VB) of AgBr (Fig. 9(a)). According to previous literature, part of the photo-excited electrons will transfer to the surface of RGO, leading to the decrease of the recombination of photo-excited electrons and photo-excited holes. ${ }^{56}$ However, the existence of boron atoms in RGO will further enhance the electron transfer efficiency and electronic conductivity, and thus restrain the recombination of photo-excited electrons and holes. Since no transitional state exists on the photo-reductive process of $\mathrm{Cr}^{\mathrm{VI}},{ }^{56}$ the electrons stored in B-RGO and the $\mathrm{CB}$ of $\mathrm{AgBr}$ will be directly captured by $\mathrm{Cr}^{\mathrm{VI}}$ in solution, and form $\mathrm{Cr}^{\mathrm{III}}$. Simultaneously, the rest of photo-excited holes at the $\mathrm{VB}$ of $\mathrm{AgBr}$ will be depleted by hole scavenger tartaric acid (TA) to be converted into $\mathrm{TA}^{\circ}{ }^{\circ}{ }^{60} \mathrm{As}$ irradiation time goes by, $\mathrm{Ag}^{0}$ begins to emerge on the surface of $\mathrm{AgBr}$. The SPR effect of $\mathrm{Ag}^{0}$ is beneficial to the photoreduction of $\mathrm{Cr}^{\mathrm{VI}}$. Due to SPR effect of $\mathrm{Ag}^{0}$, more extra electrons will be provided to the photoreduction system, which can also promote the separation of photo-excited electrons and holes in $\mathrm{AgBr}{ }^{57}$ Therefore, the improvement of photocatalytic property of $\mathrm{AgBr} /$ B-RGO upon cycling numbers can be explained by the Surface Plasmon Resonance (SPR) effect of $\mathrm{Ag}^{0}$ produced from $\mathrm{AgBr}$ during photocatalysis tests. As the reaction processes, more and more $\mathrm{Ag}^{0}$ can be generated under light irradiation, providing more extra electrons to reduce $\mathrm{Cr}^{\mathrm{VI}}$. As for the value of $k_{\mathrm{a}}$, it keeps a slow growth, even though there exists a tiny decrease
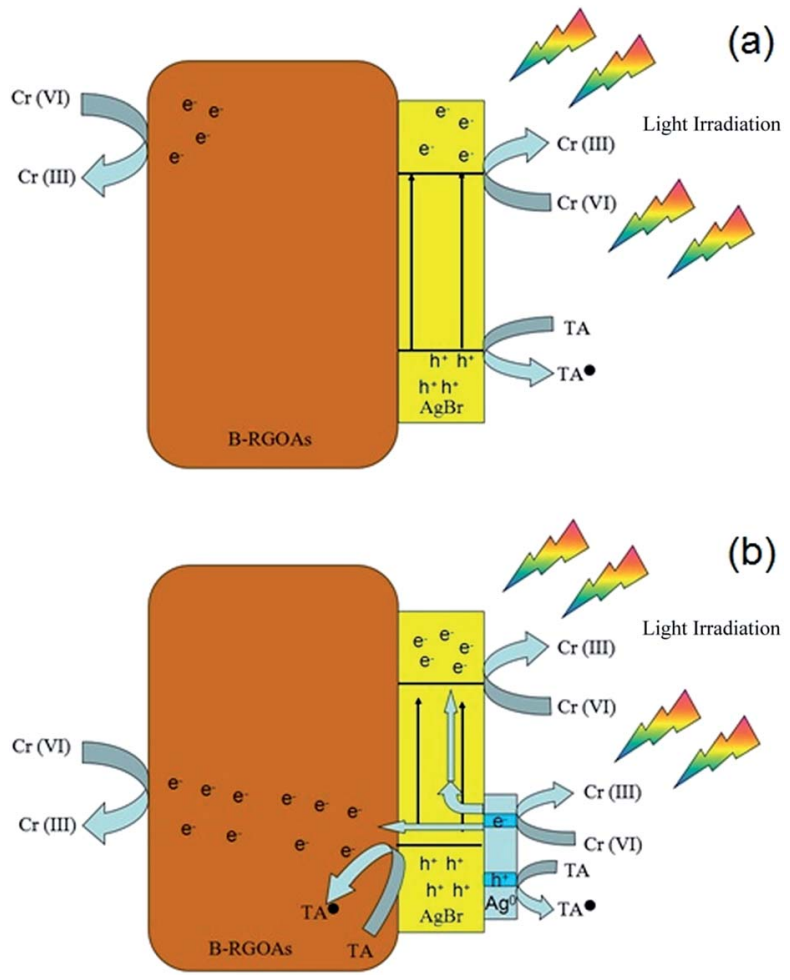

Fig. 9 Schematic explanation of the photoreduction process of $\mathrm{Cr}^{\mathrm{Vl}}$ over AgBr/B-RGO before (a) and (b) after the emergence of $\mathrm{Ag}^{\mathrm{O}}$.

during the third test. This could be caused by the tiny loss of $\mathrm{AgBr} / \mathrm{B}-\mathrm{RGO}$ during the cycling test.

\section{Conclusions}

In conclusion, $\mathrm{AgBr}$ nanoparticles on boron-doped reduced graphene oxide aerogels (AgBr/B-RGO) have been successfully synthesized by a facile hydrothermal method. Owing to the introduction of boron atoms, the electron transfer efficiency and electronic conductivity are improved, leading to the depression of the recombination of photo-excited electrons and holes, thus enhance the photoreduction of $\mathrm{Cr}^{\mathrm{VI}}$. In the cycling photocatalysis, the photocatalytic efficiency grows gradually, attributed to the production of $\mathrm{Ag}^{0}$ from the reaction of the decomposition of $\mathrm{AgBr}$ under light irradiation, bringing in Surface Plasmon Resonance (SPR) effect in the system. The approach here reported would be extended to the design and fabrication of other photocatalysis system with high photocatalytic performance, based on the combination of B-doped reduced graphene oxide matrix as well as SPR induced effect.

\section{Acknowledgements}

The authors gratefully acknowledge the financial support of National Key R\&D Program of China (2016YFA0202900), the National Science Foundation of China (51672173), and Science and Technology Planning Project of Guangdong Province (2016A010103018). We also thank Shanghai Jiao Tong University (SJTU) Instrument Analysis Center for material analyses. 


\section{Notes and references}

1 K. S. Novoselov, A. K. Geim, S. V. Morozov, D. Jiang, Y. Zhang, S. V. Dubonos, I. V. Grigorieva and A. A. Firsov, Science, 2004, 306, 666-669.

2 K. Novoselov, D. Jiang, F. Schedin, T. Booth, V. Khotkevich, S. Morozov and A. Geim, Proc. Natl. Acad. Sci. U. S. A., 2005, 102, 10451-10453.

3 Q. Xiang, J. Yu and M. Jaroniec, Chem. Soc. Rev., 2012, 41, 782-796.

4 Z. Xiong, L. L. Zhang, J. Ma and X. Zhao, Chem. Commun., 2010, 46, 6099-6101.

5 H. Zhang, X. Lv, Y. Li, Y. Wang and J. Li, ACS Nano, 2009, 4, 380-386.

6 Y. Wen, H. Ding and Y. Shan, Nanoscale, 2011, 3, 4411-4417.

7 J. Hassoun, F. Bonaccorso, M. Agostini, M. Angelucci, M. G. Betti, R. Cingolani, M. Gemmi, C. Mariani, S. Panero and V. Pellegrini, Nano Lett., 2014, 14, 4901-4906.

8 C. Petridis, D. Konios, M. M. Stylianakis, G. Kakavelakis, M. Sygletou, K. Savva, P. Tzourmpakis, M. Krassas, N. Vaenas and E. Stratakis, Nanoscale Horiz., 2016, 1, 375382.

9 K. T. Cho, G. Grancini, Y. Lee, D. Konios, S. Paek, E. Kymakis and M. K. Nazeeruddin, ChemSusChem, 2016, 9, 3040-3044.

10 N. Vaenas, D. Konios, T. Stergiopoulos and E. Kymakis, RSC Adv. , 2015, 5, 107771-107776.

11 M. Sygletou, P. Tzourmpakis, C. Petridis, D. Konios, C. Fotakis, E. Kymakis and E. Stratakis, J. Mater. Chem. A, 2016, 4, 1020-1027.

12 J. Sun, H.-W. Lee, M. Pasta, H. Yuan, G. Zheng, Y. Sun, Y. Li and Y. Cui, Nat. Nanotechnol., 2015, 10, 980-985.

13 C. Chung, Y.-K. Kim, D. Shin, S.-R. Ryoo, B. H. Hong and D.-H. Min, Acc. Chem. Res., 2013, 46, 2211-2224.

14 V. Tozzini and V. Pellegrini, Phys. Chem. Chem. Phys., 2013, 15, 80-89.

15 G. Viskadouros, D. Konios, E. Kymakis and E. Stratakis, $R S C$ Adv., 2016, 6, 2768-2773.

16 D. A. Reddy, J. Choi, S. Lee, R. Ma and T. K. Kim, RSC Adv., 2015, 5, 18342-18351.

17 G. Williams, B. Seger and P. V. Kamat, ACS Nano, 2008, 2, 1487-1491.

18 Q. Li, B. Guo, J. Yu, J. Ran, B. Zhang, H. Yan and J. R. Gong, J. Am. Chem. Soc., 2011, 133, 10878-10884.

19 N. Zhang, Y. Zhang and Y.-J. Xu, Nanoscale, 2012, 4, 57925813.

20 K. Zhou, Y. Zhu, X. Yang, X. Jiang and C. Li, New J. Chem., 2011, 35, 353-359.

21 Y. Chen, X. Zhang, D. Zhang, P. Yu and Y. Ma, Carbon, 2011, 49, 573-580.

22 Y. Liu, D. Zhang, Y. Shang, W. Zang and M. Li, RSC Adv., 2015, 5, 104785-104791.

23 R. Giovannetti, E. Rommozzi, M. Zannotti, C. D'Amato, S. Ferraro, M. Cespi, G. Bonacucina, M. Minicucci and A. Di Cicco, RSC Adv., 2016, 6, 93048-93055.

24 M. Sarro, M. Cerruti, P. Calza and L. Anfossi, RSC Adv., 2016, 6, 49845-49851.
25 B. Panigrahy and D. Sarma, RSC Adv., 2015, 5, 8918-8928.

26 Z. Chen, N. Zhang and Y.-J. Xu, CrystEngComm, 2013, 15, 3022-3030.

27 T. Kavitha, A. I. Gopalan, K.-P. Lee and S.-Y. Park, Carbon, 2012, 50, 2994-3000.

28 X. An, C. Y. Jimmy, Y. Wang, Y. Hu, X. Yu and G. Zhang, J. Mater. Chem., 2012, 22, 8525-8531.

29 B. Weng, J. Wu, N. Zhang and Y.-J. Xu, Langmuir, 2014, 30, 5574-5584.

30 M. E. Khan, M. M. Khan and M. H. Cho, $R S C A d v ., 2016,6$, 20824-20833.

31 F. Liu, X. Shao, J. Wang, S. Yang, H. Li, X. Meng, X. Liu and M. Wang, J. Alloys Compd., 2013, 551, 327-332.

32 L. Jia, D.-H. Wang, Y.-X. Huang, A.-W. Xu and H.-Q. Yu, J. Phys. Chem. C, 2011, 115, 11466-11473.

33 Z. Gao, N. Liu, D. Wu, W. Tao, F. Xu and K. Jiang, Appl. Surf. Sci., 2012, 258, 2473-2478.

34 B. Tian and J. Zhang, Catal. Surv. Asia, 2012, 16, 210-230.

35 C. Zeng, B. Tian and J. Zhang, J. Colloid Interface Sci., 2013, 405, 17-21.

36 Y. T. Liang, B. K. Vijayan, K. A. Gray and M. C. Hersam, Nano Lett., 2011, 11, 2865-2870.

37 Y. Zhang, N. Zhang, Z.-R. Tang and Y.-J. Xu, Phys. Chem. Chem. Phys., 2012, 14, 9167-9175.

38 L. K. Putri, W.-J. Ong, W. S. Chang and S.-P. Chai, Appl. Surf. Sci., 2015, 358, 2-14.

39 C. Li and G. Shi, Nanoscale, 2012, 4, 5549-5563.

40 P. Chen, T.-Y. Xiao, H.-H. Li, J.-J. Yang, Z. Wang, H.-B. Yao and S.-H. Yu, ACS Nano, 2011, 6, 712-719.

41 B. Han, S. Liu, Z.-R. Tang and Y.-J. Xu, J. Energy Chem., 2015, 24, 145-156.

42 F. Meng, J. Li, S. K. Cushing, M. Zhi and N. Wu, J. Am. Chem. Soc., 2013, 135, 10286-10289.

43 Z. Mou, Y. Wu, J. Sun, P. Yang, Y. Du and C. Lu, ACS Appl. Mater. Interfaces, 2014, 6, 13798-13806.

44 D. Qu, M. Zheng, P. Du, Y. Zhou, L. Zhang, D. Li, H. Tan, Z. Zhao, Z. Xie and Z. Sun, Nanoscale, 2013, 5, 12272-12277.

45 Z.-R. Tang, Y. Zhang, N. Zhang and Y.-J. Xu, Nanoscale, 2015, 7, 7030-7034.

46 M. Xing, W. Fang, X. Yang, B. Tian and J. Zhang, Chem. Commun., 2014, 50, 6637-6640.

47 M. Xing, F. Shen, B. Qiu and J. Zhang, Sci. Rep., 2014, 4, 6341. 48 C. Zhang, N. Mahmood, H. Yin, F. Liu and Y. Hou, Adv. Mater., 2013, 25, 4932-4937.

49 L. Zhao, M. Levendorf, S. Goncher, T. Schiros, L. Palova, A. Zabet-Khosousi, K. T. Rim, C. Gutierrez, D. Nordlund and C. Jaye, Nano Lett., 2013, 13, 4659-4665.

50 M. Xing, X. Li and J. Zhang, Sci. Rep., 2014, 4, 5493.

51 Y.-B. Tang, L.-C. Yin, Y. Yang, X.-H. Bo, Y.-L. Cao, H.-E. Wang, W.-J. Zhang, I. Bello, S.-T. Lee and H.-M. Cheng, ACS Nano, 2012, 6, 1970-1978.

52 K. Gopalakrishnan, H. M. Joshi, P. Kumar, L. Panchakarla and C. Rao, Chem. Phys. Lett., 2011, 511, 304-308.

53 Y. Ku and I.-L. Jung, Water Res., 2001, 35, 135-142.

54 S. Chakrabarti, B. Chaudhuri, S. Bhattacharjee, A. K. Ray and B. K. Dutta, Chem. Eng. J., 2009, 153, 86-93. 
55 L. Wang, N. Wang, L. Zhu, H. Yu and H. Tang, J. Hazard. Mater., 2008, 152, 93-99.

56 Y. Fan, W. Ma, D. Han, S. Gan, X. Dong and L. Niu, Adv. Mater., 2015, 27, 3767-3773.

57 P. Wang, B. Huang, X. Zhang, X. Qin, H. Jin, Y. Dai, Z. Wang, J. Wei, J. Zhan and S. Wang, Chem.-Eur. J., 2009, 15, 18211824.
58 B. Cai, X. Lv, S. Gan, M. Zhou, W. Ma, T. Wu, F. Li, D. Han and L. Niu, Nanoscale, 2013, 5, 1910-1916.

59 Y. Xue, D. Yu, L. Dai, R. Wang, D. Li, A. Roy, F. Lu, H. Chen, Y. Liu and J. Qu, Phys. Chem. Chem. Phys., 2013, 15, 1222012226.

60 R. Djellabi and M. Ghorab, Desalin. Water Treat., 2015, 55, 1900-1907. 